\title{
Iglesia y Estado en Jalisco durante la República Restaurada y el Porfiriato
}

\author{
José María Muriá
}

\begin{abstract}
A
partir del triunfo de la República, en 1867, sobre el desafortunado imperio de Maximiliano con el que tan involucrada estuvo la jerarquía eclesiástica mexicana, las relaciones entre Iglesia y Estado fueron adquiriendo en Jalisco ciertas peculiaridades que, sin llegar a ser del todo diferentes a las que predominaron en otras partes de México, sí alcanzaron honduras que las hicieron más complejas y contradictorias, hasta el extremo de convertir esta parte de México en núcleo vital para el intento que más tarde haría la Iglesia de reconquistar de facto privilegios que era mucho más difícil recuperar en el terreno de las leyes.

Pronto se percató el alto clero mexicano de que la oposición frontal y abierta a los liberales triunfantes y a las Leyes de Reforma (aplicadas desde tiempo atrás pero elevadas al rango constitucional en 1873), le acarrearía más perjuicios que utilidades y optó por hacer pública su aceptación del nuevo orden legal. De este modo, ahora con base en el papel de mártir, la Iglesia procuró conservar el respaldo masivo de sus comulgantes recurriendo a una conducta mucho más sutil que la de antaño.

Desde la década de los sesenta, antes que en otros lados, la arquidiócesis de Guadalajara (creada por Pío IX precisamente en plena intervención francesa para favorecer a los conservadores mexicanos) instituyó, por una parte, los "arreglos de conciencia" con la finalidad de recuperar el máximo posible del capital que había perdido a causa de la expropiación de bienes inmuebles decretada en su contra, pues por una suma de dinero podían ser preservados por los nuevos propietarios sin que corrieran peligro de perder el alma; por la otra, los "contradocumentos", que certificaban ser la Iglesia la verdadera dueña de una propiedad pero posibilitaban que estuviera a nombre de algún particular para evitar el riesgo de que pasara a manos del gobierno. Estas transacciones cobraron auge en la década de los ochenta y se mantuvieron vigentes por lo menos hasta el advenimiento de la Revolución Mexicana.

Con los "arreglos de conciencia" y los "contradocumentos" se dieron pues los primeros pasos conducentes a socavar el poder oficial que las autoridades civiles no lograron o no quisieron evitar, dando pie a que se abrieran amplios cauces a la reacción eclesiástica. Así, ya en 1869, cuando asumió sus funciones como segundo arzobispo de Guadalajara Pedro Loza y Pardavé (después de la muerte de Pedro Espinoza y Dávalos), la arquidiócesis tapatía estaba en el umbral de la desubstanciación de las leyes que tan grande ámpula habían levantado una década atrás.

Fue precisamente este prelado quien se dio a la tarea de conseguir el acoplamiento de su institución con las circunstancias sociopolíticas prevalecientes, procurando sobre todo no entablar pleito directo con las autoridades civiles. El fue quien usó a discreción otra componenda conocida como la "contraprotesta", mediante la cual el empleado público que había jurado la Constitución y las Leyes de Reforma se retractaba en privado, pero por escrito, ante las autoridades eclesiásti-
\end{abstract}


cas. De esta manera, en caso necesario, el arzobispo podía denunciarlo y hacerle perder el empleo.

Poco a poco las operaciones de la arquidiócesis se extendieron hasta cubrir las áreas afectadas por el movimiento reformador, siendo las primeras aquellas que resultaban vitales para la perpetuación de los ideales católicos: en 1871, apenas vuelto del Concilio Ecuménico Vaticano I, Loza mostró gran "empeño... en que las parroquias establecieran escuelas primarias" endereżadas hacia "la cristiana enseñanza de la niñez y de la juventud". 1

Para 1873, tales planteles habían proliferado por toda la arquidiócesis, pero no fue sino hasta 1874 cuando empezó a funcionar la primera escuela parroquial en la ciudad de Guadalajara. Manifiesta fue la preferencia primera del arzobispado por el establecimiento de las escuelas parroquiales en poblaciones pequeñas, antes y en mayor número que en la ciudad sede, debido a que en ellas habría de encontrar menos resistencia gubernamental.

Maniatando funcionarios públicos menores con "contraprotesta" convirtiendo a legos en salvaguarda de sus intereses económicos por medio de los "arreglos de conciencia" y de los "contradocumentos", implantando el sistema de escuelas parroquiales para propagar con mayor eficacia su ideología y mejor defender la moral cristiana del "mortal ataque liberal" construyendo los recintos necesarios donde los fieles practicantes satisficieran sus necesidades espirituales, la Iglesia católica tendió en Jalisco los puntales que precisaba mantenerse en su sitio sin ser acusada de desobedecer flagrantemente las disposiciones legales a que estaba sujeta.

Los frutos de este conjunto de artificios se patentizaron el 16 de enero de 1875 , cuando el gobierno de Jalisco prohibió la recolección de diezmos fuera de los templos, a fin de reducir los ingresos de la Mitra a lo que buenamente quisieran dar los feligreses. Sin embargo "en ningún punto de la arquidiócesis hubo obediencia a la ley o a la circular relativas a los diezmos". "Muchas autoridades locales prefirieron proceder prudentemente sin herir a la Iglesia católica, por lo que estaban dispuestas a tolerar la recolección en la mayoría de los pueblos". ${ }^{2}$

En consecuencia, no sólo no menguaron los ingresos diezmales, sino que incluso aumentaron de 508 mil pesos percibidos durante 1870 y 1874 a 840 mil recolectados en el cuatrienio siguiente. ${ }^{3}$

$\mathrm{El}$ mismo incremento habría de sobrevivir con otros ingresos provenientes de misas, bautizos, matrimonios y demás sacramentos, a pesar de haberse establecido la obligación de recibir lo que los fieles quisieran buenamente aportar.

De hecho, al iniciarse el gobierno de Porfirio Díaz, a pesar de haber perdido por completo el control de los cementerios, la Iglesia habia ya logrado sortear muchas limitantes de las leyes reformistas, pero puede decirse que fue después, gracias a los obstáculos eliminados por la "política de conciliación" de Díaz, cuando acabó por recuperar casi toda su fuerza anterior.

En 1877, al tomar Porfirio Díaz la presidencia, el sistema de escue-

1 José Ignacio Dávila Garibi, Apuntes para la historia de la Iglesia en Guadalajara, t. IV, México, Cultura, 1967, p. 1140 y 1189.

2 Joseph Robert Juárez, Conflict and cooperation between church and state: the Archbishopric of Guadalajara during the Porfiriato: 1876-1911, Austin, The University of Texas Press (tesis), 1967, p. 32-33.

3 Joseph Robert Juárez, loc. cit. , 
las parroquiales seguía experimentando un progreso notable: Guadalajara tenía ya $8^{4}$ de las 18 que alcanzó a tener en $1898 .^{5}$ Como ahora Pedro Loza se sentía mucho más seguro, de no sufrir un repudio, eran las escuelas de Guadalajara las financiadas por el obispo, mientras que las del resto de la diócesis, que también aumentarían en gran proporción, debían ser mantenidas mayormente por la propia feligresía, a pesar de que, desde 1874, las autoridades eclesiásticas habían decidido destinar una parte de los diezmos a su patrocinio. ${ }^{6}$ Lo que sucedía era que las ceremonias del culto volvían a realizarse con igual ostentación que en tiempos idos y la cantidad asignada en realidad al sustento de las escuelas se veía notablemente mermada por los gastos del alto clero y del culto externo.

Aunque hubo veces en que no quedó más remedio que doblegarse ante los requerimientos gubernamentales $y$, en términos generales, las demás actividades eclesiásticas fueron realizadas de manera menos tangible que la educativa, no por eso dejaron de contribuir a la adquisición de la fuerza que permitió a la clerecía jalisciense la inobservancia frecuente de los preceptos constitucionales. De hecho, tan sólo recibieron castigo contravenciones de gran ostentación pero de poca monta.

Por ello los propios mandatarios eclesiásticos, salvados los escollos que amenazaban la existencia institucional de la Iglesia católica, trataron de que las demostraciones del culto público se realizaran conforme a lo establecido por la ley, a efecto de no arriesgar las conquistas obtenidas en asuntos de verdad importantes.

Por otro lado, el presidente de la República también se vio dispuesto a tolerar una que otra violación insignificante a las Leyes de Reforma en aras de no provocar "alteraciones innecesarias en la paz porfiriana"?

Lo cierto es que la política impuesta por Pedro Loza en su jurisdicción había dado sus frutos: los clérigos desempeñaban sus encomiendas en la mayoría de las parroquias foráneas sin grandes contratiempos, mientras en la sede del arzobispado el prelado contaba con el respaldo del pueblo en general y con el respeto de las autoridades civiles. Así se mostró en, 1888 , al solemnizar sus bodas de oro sacerdotales y recibir evidentes muestras de lealtad y cariño de todos los sectores de la población. En vista de las grandes proporciones que alcanzaron los festejos, el clero pudo quedar satisfecho de que "el Supremo Gobierno y la Autoridad Política, presentaron su valiosa cooperacion, para cuidar el orden y evitar los accidentes que de ordinario ocurren en casos semejantes". 8

Cinco años después del fastuoso aniversario, Pedro Loza debió de presentir que sus fuerzas llegaban al final y presentó su renuncia como arzobispo de Guadalajara, pero Roma decidió no aceptársela. La salud del arzobispo "fue empeorando poco a poco" hasta morir a fines de 1898. En el cortejo fúnebre, entre los familiares y los canónigos, iba Luis C.

4 En mayo de 1874 se había creado incluso una Junta Directiva de Instrucción Primaria Parroquial presidida por el canónigo Florencio Parga.

5 Diana Romero de Swain, "Las escuelas parroquiales de Guadalajara.1873-1898", en Boletín del Archivo Histórico de Jalisco, vol. IV, núm. 3, Guadalajara, Gobierno del Estado de Jalisco, septiembre-diciembre de 1980, p. 14.

6 José Ignacio Dávila Garibi, op. cit, p. 1227.

7 Antonio Rius Facius, De Don Porfirio a Plutarco. Historia de la A.C.J.M., Prol. de José González Torres, México, Jus, 1958, p. XII.

8 José Ignacio Dávila Garibi, op. cit., p. 1199-1201. 
Curiel, gobernador del estado; no se permitió que fuese sepultado en la Catedral. $^{9}$

Hasta los inicios del siglo $\mathrm{XX}$, la jerarquía eclesiástica pareció conforme con las condiciones imperantes y sus relaciones con el Estado parecían haber alcanzado el equilibrio necesario para que ambos cumplieran pacíficamente sus funciones, pero en la primera oportunidad el clero reasumió su beligerancia e intransigencia.

En febrero de 1900, Jacinto López y Romo fue nombrado tercer arzobispo de Guadalajara; sólo permaneció en el cargo nueve meses, pues su muerte acaeció el último día del siglo. Su preocupación por la enseñanza primaria lo llevó a aprobar, "un nuevo plan de estudios para las escuelas parroquiales no sólo correspondiente al que regía en la enseñanza oficial sino en ciertos puntos más amplios que éste". ${ }^{10}$

A fin de cuentas, el exito de estos establecimientos engendró la idea de manejar no sólo la educación elemental, sino también el adiestramiento de quienes la impartieran. Para tal efecto, López y Romo inició la construcción de un edificio para la Escuela Normal de Profesores Católicos y prometió fundar una Escuela Normal de Profesores Ortodoxos. Ambas instituciones quedaron en proyecto a causa de su muerte, pero la edificación iniciada se aprovecharía para instalar allí la Escuela Normal Católica para Señoritas en 1902, a iniciativa de José de Jesús Ortiz, cuarto arzobispo de Guadalajara. ${ }^{11}$

Quizá lo más sobresaliente de la gestión de López fue la tolerancia con otras religiones: el gobierno del estado permitió la apertura de un templo evangelista en el apartado municipio de Colotlán, lo cual se llevó a efecto sin que se registrara ninguna reacción hostil de parte de las autoridades eclesiásticas. ${ }^{12}$ Sin embargo, esta actitud tolerante cambiaría por completo años después, cuando hechos menos amenazantes dieron lugar a protestas que llegaron a convertirse en verdaderos motines.

En realidad, durante la primera década del siglo XX empezaron a patentizarse los anhelos reivindicativos de la preeminencia eclesiástica, bajo el influjo de la encíclica Rerum Novarum, expedida por León XIII en 1891.

Desde su divulgación en México, este documento fue motivo de gran polémica en virtud del cambio que preconizaba en cuanto a la posición de la Iglesia con respecto a las relaciones obrero-patronales, puesto que formulaba severas críticas a los excesos del capitalismo y proclamaba "el derecho de los trabajadores a una justa retribución y a otras compensaciones materiales y espirituales". Declaraba, además, libres de cualquier sujeción ajena a la Iglesia, a todas las asociaciones católicas. ${ }^{13}$

Polémicas aparte, lo cierto es que la encíclica brindó a la Iglesia católica mexicana la oportunidad de sobrepasar la acción del Estado en beneficio del mejoramiento de las condiciones de vida de los trabajadores, lo cual significaba aproximarse a un dominio político que le era vedado. ${ }^{14}$

En medio de este nuevo motivo de divergencias, Guadalajara reci-

9 Gaceta Mercantil, Guadalajara, 1898.

10 José Ignacio Dávila Garibi, op. cit., p. 1309

11. Zenaido Michel Pimienta, Del cometa del 82 a los satélites artificiales, Guadalajara, ed. del Autor, 1975, p. 40-42.

12 Archivo Histórico de Jalisco, Gobernación 1900.

13 Alicia Olivera Sedano, Aspectos del conflicto religioso de 1926 a 1929. Sus antecedentes y consecuencias, México, Instituto Nacional de Antropología e Historia, 1966 (Historia XVI), p. 13.

14 Jean Meyer, La cristiada, 4a. ed. México, Siglo XXI, 1976, t. II, p. 46. 
bió a su cuarto arzobispo, José de Jesús Ortiz y Rodríguez, quien arribó a principios de enero de 1902, justo cuando terminó el Primer Congreso Católico Nacional que se encaminó a buscar el modo de aplicar la Rerum Novarum. Se trató en ese Congreso de "la reglamentación de los círculos católicos, de los problemas obreros, de la beneficencia, del alcoholismo, de la prensa católica, de los recreos populares, y de la instrucción pública". En él participó de manera destacada el delegado por Jalisco, Miguel Palomar y Vizcarra, quien propuso por primera vez en México la creación de las Cajas Reiffeisen. ${ }^{15}$

Probablemente a raíz del susodicho evento, el interés del arzobispado de Guadalajara por las escuelas parroquiales se acentuó sobremanera, pues no vaciló en imponer su autoridad sobre el Cabildo eclesiástico a fin de redistribuir los diezmos de modo tal que pudiera disponerse de una cantidad mayor para la mejora y sostenimiento de tales planteles.

Asimismo, reorganizó el Boletín Eclesiástico, dándole el nombre de Boletín Eclesiástico y Científico del Arzobispado de Guadalajara a partir de 1904, año en que, con su ayuda "material y moral", apareció $E l R e$ gional, "primer diario católico con que contó Guadalajara", que llegó a alcanzar mayor circulación que cualquier otro. ${ }^{16}$

El Segundo Congreso Católico tuvo lugar en Morelia en 1904 y, dos años después, en octubre, se efectuó en Guadalajara el Tercer Congreso Católico Nacional y Primero Eucarístico, donde se dieron las siguientes conclusiones:

Obligación del patrono de tratar al obrero como igual que él y de respetar su dignidad personal; obligación de concederle el descanso dominical y de crear escuelas para la instrucción de los obreros y sus hijos; obligación de pagar su salario íntegro y en dinero en efectivo. Además se proclamó que el justo salario individual nunca debía descender del salario mínimo y debía ser suficiente para el sostenimiento de un obrero honrado y sobrio.

Como debe suponerse, no faltaron clérigos contrarios a tales conclusiones, mayormente la referida al derecho de recibir un salario justo. Incluso se pensó en retirarla no por "falta de valor cristiano", sino porque contrariaba la política laboral del presidente. ${ }^{17}$

Hasta 1903, los jerarcas clericales siguieron afanados en que las manifestaciones del fervor católico no rebasaran los límites establecidos, llegándose incluso a la suspensión de procesiones o fiestas cuando para su celebración las autoridades no daban su franca anuencia. Asimismo, la mayoría de los curas de las parroquias foráneas se habían abstenido normalmente, por órdenes superiores, de inmiscuirse en asuntos ajenos a su ministerio.

Pero la lucha de la Iglesia por la reivindicación de los obreros, provocó también que la clerecía de Jalisco asumiera una posición más aguerrida en asuntos del culto público. A partir del Primer Congreso referido empezaron a menudear los casos de desobediencia a las limitaciones legales del culto externo, hasta el grado de que ciertos curas se enfrentaron más de una vez a las autoridades civiles, sin que el arzobispo ni nadie pusiera remedio.

Asimismo, la intolerancia católica se hizo de nuevo presente con

15 Alicia Olivera Sedano, op. cit., p. 34; Zenaido Michel Pimienta, op. cit., t. IV, p. 74, 16 Juan B. Iguíniz, El periodismo en Guadalajara, 1809-1915, Guadalajara, Universidad de Guadalajara, 1955, t. II, p. 291.

17 Joseph Robert Juárez, op. cit., p. 261-262. 
agresiones frecuentes de palabra y obra a ministros y fieles protestantes. ${ }^{18}$ También, a partir de entonces, cobró nuevo impulso la educación clerical, se organizó mejor la prensa católica y se formalizó la existencia en Guadalajara de los Círculos Obreros Católicos que tenían la misión de "difundir una versión católica del mutualismo y del cooperativismo, cuyo objetivo era ligar más al obrero con la iglesia". 19

Los trastornos causados por los párrocos foráneos subieron de tono a principios de 1905, mas el poder público parecía no querer darse cuenta de tal rebeldía, de manera que los informes anuales rendidos por los presidentes municipales al gobernador, hasta 1907, sostenían no haber tenido la paz pública más contravenciones que los delitos del orden común. ${ }^{20}$

Por otra parte, a fines de 1905 se expidió un decreto que derogaba la prohibición impuesta a las asociaciones de beneficencia privada para adquirir y administrar bienes inmuebles, ${ }^{21}$ lo cual vino a facilitar aún más las operaciones de este tipo que ya practicaba rutinariamente el arzobispado de Guadalajara. ${ }^{22}$

Como quiera, las frecuentes y casi siempre violentas infracciones a las leyes del culto público, dieron lugar a que el gobierno del Estado reimprimiera, al mediar 1906, el texto legislativo que en forma expresa prohibía la realización de actos religiosos en los atrios de los templos y en los panteones, aun cuando aquéllos estuvieran cercados y éstos estuvieran anexos a las iglesias. ${ }^{23} \mathrm{O}$ bien la medida surtió efecto o, ante la proximidad de la celebración del Congreso Católico de Guadalajara, los sacerdotes decidieron no causar problemas hasta terminada la reunión, pero el caso es que no se suscitó ningún incidente durante el resto del año de 1906.

Pero apenas entrado el año siguiente, las confrontaciones entre clérigos rurales y autoridades municipales por motivos en apariencia religiosos, se tornaron cada vez más frecuentes, lo que no era sino el reflejo del poder que había recuperado el arzobispado de Guadalajara al acaudillar las causas de las clases trabajadoras que, ante la indiferencia del régimen a sus necesidades, no vacilaron en afiliarse a las organizaciones que iban surgiendo de los congresos católicos.

De tal suerte, ya para 1907, el gobierno de Jalisco se encontraba ante una formidable organización clerical que intervenía en casi todas las actividades e incluso ponía en tela de juicio numerosas disposiciones gubernamentales.

Por otra parte, las organizaciones católicas mutualistas y de "mejoramiento colectivo" cobraban cada día mayor empuje. Si bien su intención no era la de promover una revolución violenta, puesto que se reducía a una especie de educación de los trabajadores para que, unidos, se ayudaran efectivamente en sus necesidades y para acostumbrarlos al ahorro y a las prácticas parlamentarias, ${ }^{24}$ el resultado puso a la arquidiócesis de Guadalajara a la cabeza de un movimiento que empezó a efectuar cam-

18 Archivo Histórico de Jalisco, Gobernación 1904.

19 Barry Carr, El movimiento obrero y la polftica en México 1910-1929, t. II, México, Sepsetentas, 1976, p. 97.

20 Archivo Histórico de Jalisco, Gobernación 1904 a 1907.

21 El Estado de Jalisco, Guadalajara, 25 de febrero de 1906.

22 Joseph Robert Juárez, op. cit, p. 154.

23 El Estado de Jalisco, Guadalajara, 3 de junio de 1906.

24 José G. Zuno, Historia de la Revolución en el estado de Jalisco, México, Instituto Nacional de Estudios Históricos de la Revolución Mexicana, 1964, p. 30. 
bios importantes en las relaciones sociales, económicas y políticas de los jaliscienses.

El ultimo congreso católico tuvo lugar en Oaxaca al comenzar 1909. En él se propuso instituir una jornada de trabajo de siete, ocho o nueve horas, según el sexo y la edad del trabajador, así como el tipo de labor por desempeñar. También se trataron los problemas de "los accidentes de trabajo; los medios para evitar el juego, la embriaguez y las riñas; la difusión de la higiene industrial y el derecho de huelga." 25

Las soluciones propuestas debieron de haber parecido demasiado atrevidas y, para no provocar represalias de parte del poder civil, "los obispos y arzobispos asistentes declararon en una carta pastoral colectiva que estos congresos no eran cámaras legislativas, y menos el poder ejecutivo; por tanto, su único objeto era estrechar lazos entre los laicos y orientar el estudio de los problemas sociales." 26 De este modo pretendía la Iglesia propalar que sus intereses radicaban nada más en el mejoramiento de las condiciones sociales prevalecientes y dejar bien sentado que los asuntos políticos no la inquietaban. Sin embargo, en su conjunto, los resolutivos adoptados en los cuatro congresos católicos celebrados, muestran que la nueva jerarquía estaba decidida a que el catolicismo retomara un papel hegemónico en la vida pública mexicana, convertido en un agente de progreso. ${ }^{27}$

Como es sabido, el movimiento encabezado por Francisco I. Madero en 1910, alcanzó escasas proporciones entre los jaliscienses, en contraste marcado con el enorme respaldo que dieron éstos al Partido Católico Nacional, en cuya gestación y consolidación no, poco tuvieron que ver.

Desde 1907, el jesuita Bernardo Bergoend tenía entablado contacto con los Operarios Guadalupanos (organización fundada en Guadalajara dos años antes) a la que hizo ver "la necesidad de crear un organismo político católico, que estuviera bien organizado al producirse el desmoronamiento del porfiriato para implantar los principios de la doctrina social cívica y política de la Iglesia". ${ }^{28}$

Sin de verdad saber de dónde vendría ese desmoronamiento, los católicos siguieron agrupándose en asociaciones con tendencias cada vez más claramente políticas; así, en 1909 (año en que se celebró el congreso de Oaxaca), se estableció en el Distrito Federal el Círculo Católico Nacional "para preparar a los católicos en la necesaria actuación política". ${ }^{29}$

A pesar de las reiteradas declaraciones de Madero en el sentido de que la actividad política de los católicos quedaría garantizada en la nueva era democrática que con él iniciaría el país, la Iglesia católica y sus fieles se abstuvieron de cualquier demostración que diese la apariencia de respaldo. De la misma manera, y por igual motivo, rehusaron apuntalar a Porfirio Díaz, cuando éste trató de apresurar la creación del Partido Católico con el solo fin de disimular la represión política prevaleciente; la Iglesia católica había ya decidido esperar el momento oportuno para la fundación de su partido político.

Este llegó cuando ya la caída de don Porfirio y su régimen era cues-

25 Moisés González Navarro, Historia Modema de México, vol. IV, El porfiriato. Vida Social, México, Hermes, 1973, p. 366.

26 Moisés González Navarro, loc. cit.

27 David C. Bailey, IViva Cristo Rey!' The cristero rebellion and the Church-State conflict in Mexico, Austin University of Texas Press, 1974, Texas Pan American Series, p. 19

28 Antonio Rius Facius, op. cit., p.8

29 Antonio Rius Facius, op. cit, p. 11 
tión de pocos días: el día de la Santa Cruz (3 de mayo) de 1911, con la participación conjunta de los Operarios Guadalupanos y el Círculo Católico Nacional, quedó formalmente establecido el Partido Católico Nacional.

Libre, pues, del patrocinio presidencial y sin compromiso con Madero, la Iglesia católica pudo, al fin, luchar de nuevo legal y abiertamente para consolidarse como rectora de los destinos nacionales.

La candidatura de Madero a la presidencia de la República fue apoyada por todos los partidos políticos, pero al principio no figuró entre ellos el Católico Nacional, pues pensó en lanzar a Francisco León de la Barra con Francisco Vázquez Gómez para la vicepresidencia; mas ante la apabullante popularidad cobrada por Madero, comprendieron que no era posible el triunfo de sus candidatos y optaron también por postular a Madero, aunque lucharfan por conseguir que De la Barra obtuviese la vicepresidencia.

No obstante el apoyo que el Partido Católico Nacional acabó dando a la candidatura de Madero, la arquidiócesis de Guadalajara anidaba serios temores de lo podría sufrir la Institución. El 28 de mayo de 1911, José de Jesús Ortiz escribió al arzobispo de México comunicándole su desconfianza, pues vio que

El estricto cumplimiento de las Leyes de Reforma encaja muy bien en el programa revolucionario, sin que podamos contar ya con la tolerancia y el espíritu benévolo y conciliador del ilustre Gral. Díaz, que ha sido hasta ahora nuestra única defensa después de Dios. 30

Tres años después, los temores del prelado tapatío se vieron de sobra justificados, pero antes de eso la Iglesia mexicana habría de alcanzar un poder muy difícil de imaginar poco tiempo atrás. 